\title{
Effects of Fatty Acid Supplements on Feed Intake, and Feeding and Chewing Behavior of Lactating Dairy Cows
}

\author{
K. J. Harvatine ${ }^{1}$ and M. S. Allen ${ }^{2}$ \\ Department of Animal Science, Michigan State University, East Lansing 48824-1225
}

\section{ABSTRACT}

Saturated and unsaturated fatty acid supplements (FS) were evaluated for effects on feed intake, meal patterns, and chewing behavior. Eight ruminally and duodenally cannulated cows were used in a replicated $4 \times 4$ Latin square design experiment with 21 -d periods. Treatments were control and a linear substitution of $2.5 \%$ fatty acids from supplemented saturated FS (SAT; prilled, hydrogenated free fatty acids) for partially unsaturated FS (UNS; calcium soaps of long-chain fatty acids). All rations contained identical forage and concentrate components including $37.2 \%$ forage and $13.5 \%$ cottonseed. Dry matter intake for SAT was not different from control, whereas increasing unsaturated FS linearly decreased dry matter intake by $3.2 \mathrm{~kg}$. Wet weight of ruminal digesta decreased linearly up to $11.3 \mathrm{~kg}$ (13\%) with increasing unsaturated FS. Adding supplementary fatty acids did not change meal number, meal length, or time between meals compared with control, but increasing unsaturated FS decreased meal size 0.22 $\mathrm{kg}(9 \%)$ within FS. The SAT treatment increased time spent ruminating by $56(10 \%)$ and $42(7 \%) \mathrm{min} / \mathrm{d}$ compared with control and UNS, respectively. Increasing saturated FS did not affect frequency of rumination bouts or interval between bouts, but increased rumination bout length by $5.6 \mathrm{~min}$. Water intake was not affected by treatment, but increasing saturated FS linearly decreased the number of drinking bouts per day by up to 2.9 bouts (23\%). Increased unsaturated fatty acid flow to the duodenum decreased feed intake by decreasing meal size, and increased saturated fatty acid flow to the duodenum increased rumination time per day by increasing rumination bout length.

Key words: fatty acid saturation, rumination, feeding behavior, feed intake

\section{INTRODUCTION}

High-producing dairy cows have high energy requirements that may exceed their ability to consume dietary

\footnotetext{
Received January 13, 2005.

Accepted October 21, 2005.

${ }^{1}$ Current address: Department of Animal Science, Cornell University, Ithaca, NY 14853.

${ }^{2}$ Corresponding author: allenm@msu.edu
}

energy on some diets, resulting in less than maximum milk yield. Addition of fat to the diet increases energy density without increasing rumen acid production, or maintains energy density while increasing fiber for stabilization of rumen fermentation (Allen, 1997). Prilled saturated free fatty acids (FA) and calcium salts of FA are two manufactured products marketed to minimize effects of fat on ruminal fermentation. However, calcium salts of FA are not entirely protected in the rumen and dissociation of the calcium ion allows rumen biohydrogenation of unsaturated FA (Wu et al., 1991).

Intake is highly regulated by animal nutrient requirements and metabolic state, and by the type and temporal pattern of absorbed fuels. A meta-analysis of treatment means from the literature indicated different hypophagic effects of fat supplements differing in FA source, form, and type (Allen, 2000). Within commonly fed FA supplement (FS) sources, calcium salts of palm FA linearly decreased DMI with increasing dietary concentration, whereas hydrogenated FA did not affect DMI (Allen, 2000). The profile of FA reaching the duodenum has different effects on intake (Drackley et al., 1992) and unsaturated FA have been shown to increase plasma concentrations of the gut peptides including cholecystokinin (Choi and Palmquist, 1996) and glucagon-like-peptide-1 (Benson and Reynolds, 2001; Litherland et al., 2005) and may stimulate satiety through hepatic oxidation (Allen, 2000). Although many experiments observe daily DMI, few have observed feeding and chewing behavior. Daily feed intake is a function of meal size and intermeal interval and unsaturated FA may decrease intake through signaling decreased meal size or increased intermeal interval.

Prilled and hydrogenated free FA and calcium soaps of long-chain FA were selected to provide the largest difference in unsaturated FA, especially polyunsaturated FA (PUFA) flow to the duodenum possible with commonly available feed ingredients. Fatty acids are recognized as powerful physiologic modifiers affecting endocrine signaling and gene regulation (Drackley, 2000). Because intake is regulated by the effect of type and temporal variation of absorbed fuels (Allen, 2000) and animal metabolic state, the effects of FA on intake are complicated by the dual roles of FA as fuels and 
metabolic modifiers. The objective of this experiment was to determine effects of FA supplement saturation on feed intake and feeding and chewing behavior of lactating dairy cows. We hypothesized that increasing unsaturated FA would decrease intake through decreased meal size.

\section{MATERIALS AND METHODS}

This paper is the third of 3 papers in a series from one experiment that evaluated effects of FS differing in FA saturation. This paper discusses treatment effects on DMI and feeding and chewing behavior, and the companion papers focus on milk yield, milk FA profile and energy balance (Harvatine and Allen, 2006a), and ruminal and postruminal nutrient digestion (Harvatine and Allen, 2006b). Rumen kinetics of FA biohydrogenation is reported elsewhere (Harvatine and Allen, 2006c). Experimental procedures were approved by the All University Committee on Animal Use and Care at Michigan State University.

\section{Cows and Treatments}

Eight ruminally and duodenally cannulated multiparous Holstein cows ( $77 \pm 8.7 \mathrm{DIM}$; mean \pm SD) from the Michigan State University Dairy Cattle Teaching and Research Center were used in a replicated $4 \times 4$ Latin square design experiment. Cows were randomly assigned to treatment sequence. Treatments were a control diet containing no added FS or 2.5\% added FA as saturated (SAT; prilled, hydrogenated FA, Energy Booster 100, MS Specialty Nutrition, Dundee, IL), intermediate mixture of saturated and unsaturated (INT), or partially unsaturated (UNS) FA (Ca Soaps of LCFA, Megalac-R, Church and Dwight Company, Inc., Princeton, NJ). Treatment periods were $21 \mathrm{~d}$ with the final $11 \mathrm{~d}$ used for sample and data collection. Surgery was performed at the Department of Large Animal Clinical Science, College of Veterinary Medicine, Michigan State University. Immediately before initiation of the experiment, empty BW (ruminal digesta removed) of cows was $516 \pm 33 \mathrm{~kg}$ (mean $\pm \mathrm{SD}$ ).

Treatment mix composition and diet composition are reported in a companion paper (Harvatine and Allen, 2006a). Experimental diets contained $40 \%$ forage (66:33, corn silage: alfalfa silage), $13.5 \%$ whole cottonseed, dry ground corn, premixed protein supplement (soybean meal, corn gluten meal, and blood meal), a mineral and vitamin mix, and $\sim 5.7 \%$ control mix, saturated FS (SAT) mix, 50:50 mix of saturated and unsaturated FS (INT) mixes, or unsaturated FA (UNS). All diets were fed as a TMR once per day at $0900 \mathrm{~h}$.

\section{Data and Sample Collection}

Throughout the experiment, cows were housed in tiestalls and diets were fed as a TMR once daily at 0900 h) at $115 \%$ of expected intake. Amounts of feed offered and orts were weighed for each cow daily. Samples of all diet ingredients $(0.5 \mathrm{~kg})$ and orts from each cow (12.5\%) were collected daily on d 11 to 14 and d 16 to 19 and combined into 1 sample to represent $4 \mathrm{~d}$ for digestibility analysis (d 11 to 14 ) and $4 \mathrm{~d}$ for feeding behavior observation (d 16 to 19). During monitoring of feeding behavior (d 16 to 19), cows were milked twice daily (0600 and $1800 \mathrm{~h}$ ) in their stalls and remained in their stalls for the entire observation period.

Feeding behavior was continuously monitored from d 16 to 19 (96 h) of each period using a computerized data acquisition system (Dado and Allen, 1993). Data of chewing activities, feed disappearance, water consumption, and rumen $\mathrm{pH}$ were recorded every $5 \mathrm{~s}$ for each cow. When chewing equipment malfunctioned for an individual cow during a 24-h period $(0900 \mathrm{~h}$ to 0900 h), chewing behavior was deleted for that day. The system successfully collected $77 \%$ of the total chewing behavior data (average $3.1 \mathrm{~d}$ per cow per period). The feeding behavior analysis procedure allowed determination of meal size and length for days missing short periods of chewing data. This intervention allowed analysis of meal parameters for $88 \%$ of the observation days. Feeding behavior was determined according to Dado and Allen (1993) with the following modifications. Potential meals were identified at the 75 th percentile of the running standard deviation of the manger weight to account for differences in baseline variation among load cells. Minimum meal size was $1 \mathrm{~kg}$ (as fed) and minimum continuous meal length was $30 \mathrm{~s}$. Meal parameters determined to be outliers (outside the 10th and 90th percentile) were manually verified and corrected if determined to be in error. Daily means were calculated for number of meal bouts per day, interval between meals, meal size, eating time, ruminating time, and total chewing time. These response variables were calculated as daily means and averaged for each period. Indwelling rumen $\mathrm{pH}$ probes were calibrated daily. Data were discarded for the probe if calibration drifted $\pm 0.10 \mathrm{pH}$ units at either $\mathrm{pH} 4.0$ or $\mathrm{pH} 7.0$. Seventy-eight percent of the cow days met the criteria. Ruminal contents were evacuated manually through the ruminal cannula at $1350 \mathrm{~h}$ ( $4.5 \mathrm{~h}$ after feeding) on $\mathrm{d} 20$ and at $0700 \mathrm{~h}$ ( $2 \mathrm{~h}$ before feeding) on $\mathrm{d} 21$ of each period as described in Harvatine and Allen (2006a).

\section{Sample and Statistical Analyses}

Diet ingredients, orts, rumen contents, and duodenal digesta were processed as previously described (Harvat- 
ine and Allen, 2006b). Overall DM and nutrient intake was calculated as the means of digestibility (d 11 to 14) and feeding behavior (d 16 to 19 ) observations. The ratio of chewing activity to DM and nutrient intake used intake from feeding behavior observation only. Ruminal pool sizes (kg) of OM, NDF, indigestible NDF, and starch were determined by multiplying the concentration of each component (\% DM) by the ruminal digesta DM weight $(\mathrm{kg})$.

Digestible energy was calculated as the product of gross energy intake and digestibility as determined elsewhere (Harvatine and Allen, 2006b).

Selection was calculated as concentration of the component in the diet consumed divided by the concentration of the component in the diet fed.

All data were analyzed using the fit model procedure of JMP (Version 5, SAS Institute, Cary, NC) according to the following model:

$$
\mathrm{Y}_{\mathrm{ijk}}=\mu+\mathrm{C}_{\mathrm{i}}+\mathrm{P}_{\mathrm{j}}+\mathrm{T}_{\mathrm{k}}+\mathrm{e}_{\mathrm{ijk}}
$$

where $\mathrm{Y}_{\mathrm{ijk}}=$ dependent variable, $\mu=$ overall mean, $\mathrm{C}_{\mathrm{i}}=$ random effect of cow ( $\mathrm{i}=1$ to 8$), \mathrm{P}_{\mathrm{j}}=$ fixed effect of period ( $\mathrm{j}=1$ to 4$), \mathrm{T}_{\mathrm{k}}=$ fixed effect of treatment $(\mathrm{k}=1$ to 4$)$, and $\mathrm{e}_{\mathrm{ijk}}=$ residual error.

Period by treatment interaction was evaluated, but was removed from the statistical model when not significant $(P>0.10)$. Period by treatment interaction was not significant for any variable of primary interest; variables with significant interactions are noted in the tables. Data points with Studentized Residuals greater than 3 were considered outliers and excluded from analysis. Few points were excluded in analysis and rarely more than one per response variable. Preplanned contrasts included the effect of addition of FS (control vs. SAT, INT, and UNS), linear effect of substituting unsaturated FA for saturated FA (SAT vs. UNS), and quadratic effect of substituting unsaturated FA for saturated FA (INT vs. SAT and UNS). The preplanned contrasts did not allow individual comparison of each fat treatment to the control. Protected LSD was used for mean separation when the model treatment effect was significant. Pearson correlation coefficients were determined between cow-period observations for some parameters. Treatment effects, linear and quadratic responses, and correlations were declared significant at $P<0.05$, and tendencies were declared at $P<0.10$.

One cow developed clinical mastitis on d 19 of period 3. Feeding behavior data was already collected from this period and was included in analysis but the cow did not fully recover and data from period 4 was not used.

\section{RESULTS AND DISCUSSION}

Dietary PUFA were extensively biohydrogenated in the current experiment (Harvatine and Allen, 2006c), but decreased biohydrogenation of trans-C18:1 with increasing unsaturated FS increased duodenal flow of monounsaturated FA (Table 1). Duodenal FA flow of C18:2 did not differ between treatments, and C18:3 flow was linearly decreased with increasing unsaturated FS.

\section{Feed Intake}

Addition of FS decreased DMI compared with control $(P<0.001)$, and increasing unsaturated FS linearly decreased DMI ( $P=0.02$; Table 2$)$. Mean comparison showed that SAT had no effect on intake but UNS decreased intake compared with the control. Intake of OM, starch, and FA were similarly decreased. Neutral detergent fiber intake was less affected because of differences in NDF concentration among diets from the inclusion of rice hulls as dietary fill in balancing diets. Digestible energy intake was decreased by FS $(P=0.04)$, and tended to linearly decrease with increasing unsaturated FS $(P=0.06)$.

Allen (2000) reported that in 11 of 24 studies summarized, increasing concentrations of calcium salts of palm FA in diets decreased DMI, whereas 22 of the 24 studies had numerically lower DMI. Calcium salts of palm FA have a lower concentration of unsaturated FA and a higher C16:C18 FA ratio than the calcium salts of blended FA used in this experiment. The same study reported that hydrogenated FA or triglycerides resulted in decreased feed intake in only one experiment and increased feed intake in 2 out of 21 studies reported (Allen, 2000). This meta-analysis provides strong support for differences in hypophagic effects of different FA supplements.

Abomasal infusion of unsaturated fat consistently decreases intake relative to no fat and saturated fat infusions (Benson and Reynolds, 2001). Drackley et al. (1992) and Christensen et al. (1994) showed abomasal infusions of increasing unsaturated FA with a lower C16:C18 FA ratio decreased DM and energy intake. Fatty acid supplements in the current experiment differed in unsaturated fat concentration while maintaining similar C16:C18 ratios. Bremmer et al. (1998) demonstrated decreased intake with abomasal infusion of increasingly unsaturated FA with the same C16:C18 FA ratio. Lastly, protected oleamide FA consistently linearly decreased intake compared with free oil that is readily biohydrogenated in the rumen (Jenkins, 1998, 2000; DeLuca and Jenkins, 2000). Intake depression in the current experiment cannot be attributed to increased total flow of PUFA to the duodenum but did correspond to increased duodenal flow of both cis-C18:1 and trans-C18:1.

Increasing unsaturated FS linearly decreased milk fat synthesis by $0.27 \mathrm{~kg} / \mathrm{d}$ (Harvatine and Allen, 2006a). 
Table 1. Effects of dietary fatty acid supplements on duodenal fatty acid (FA) flow

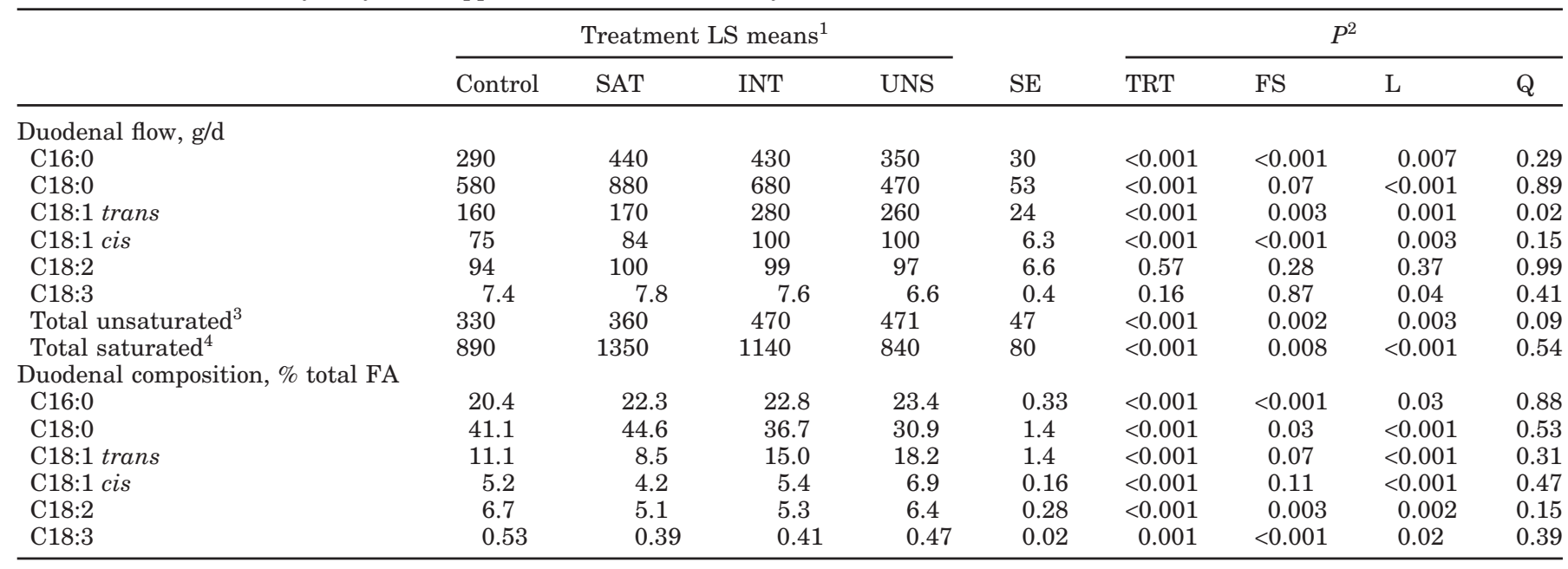

${ }^{1}$ Treatments were SAT = saturated fatty acids (FA) from prilled, hydrogenated FA; INT = intermediate saturated FA as a mix of prilled, hydrogenated FA and calcium soaps of long-chain FA (LCFA); and UNS = partially unsaturated FA fed as Ca soaps of LCFA.

${ }^{2}$ Trt = Treatment effect; FS = effect of FA supplement; L = linear effect of substituting unsaturated FA for saturated FA; and Q = quadratic effect of substituting unsaturated FA for saturated FA.

${ }^{3}$ Unsaturated fatty acids include trans C18:1, cis C18:1, C18:2, and C18:3.

${ }^{4}$ Saturated fatty acids include C14:0, C16:0, and C18:0.

Although DMI decreased and energy intake tended to decrease with increasing unsaturated FS, a greater intake depression would be expected to compensate for the large reduction in energy required for milk fat synthesis with increasing unsaturated FS. Dry matter intake was not decreased with short-term (Baumgard et al., 2002) and long-term (Perfield et al., 2002) experimentally induced milk fat depression. In addition, Shingfield et al. (2004) reported no change in heat energy production during conjugated linoleic acid-induced milk fat depression. Failure to maintain energy balance by decreasing intake with no change in heat production is expected to result in increased BW gain. In the current experiment, increasing unsaturated FS linearly increased BW gain (Harvatine and Allen, 2006a). Failure to maintain energy homeostasis may be because of metabolite balance. Intake is regulated by the type and temporal pattern of available fuels (Allen, 2000) and the interaction of available fuels and metabolic state. Enzymes involved in FA and triglyceride synthesis are decreased in the mammary gland during milk fat depression (Peterson et al., 2003) leading to decreased FA and triglyceride synthesis. Mammary nutrient use of acetate, FA, and glucose for the production of NADPH is expected to be decreased but the use of other metabolites is relatively unaffected. Neither acetate nor glucose, spared from NADPH production or through use of the acetate as an energy source, are directly oxidized

Table 2. Effects of dietary fatty acid supplements on intake of nutrients

\begin{tabular}{|c|c|c|c|c|c|c|c|c|c|}
\hline & \multicolumn{4}{|c|}{ Treatment LS means ${ }^{1}$} & \multirow[b]{2}{*}{$\mathrm{SE}$} & \multicolumn{4}{|c|}{$P^{2}$} \\
\hline & Control & SAT & INT & UNS & & TRT & FS & $\mathrm{L}$ & $\mathrm{Q}$ \\
\hline \multicolumn{10}{|l|}{ Intake, $\mathrm{kg} / \mathrm{d}$} \\
\hline $\mathrm{DM}$ & 27.3 & 25.7 & 25.1 & 24.1 & 1.0 & 0.001 & $<0.001$ & 0.02 & 0.60 \\
\hline $\mathrm{OM}$ & 24.4 & 23.0 & 22.6 & 21.6 & 0.9 & 0.001 & $<0.001$ & 0.02 & 0.61 \\
\hline $\mathrm{NDF}$ & 7.3 & 6.7 & 6.6 & 6.3 & 0.25 & $<0.001$ & $<0.001$ & 0.09 & 0.52 \\
\hline Starch & 8.2 & 7.4 & 7.3 & 7.0 & 0.3 & $<0.001$ & $<0.001$ & 0.04 & 0.64 \\
\hline Fatty acids & 1.5 & 2.1 & 2.0 & 1.8 & 0.07 & $<0.001$ & $<0.001$ & $<0.001$ & 0.68 \\
\hline $\mathrm{DE},{ }^{3} \mathrm{Mcal} / \mathrm{d}$ & 78.0 & 75.3 & 74.0 & 70.1 & 3.1 & 0.07 & 0.04 & 0.06 & 0.59 \\
\hline
\end{tabular}

\footnotetext{
${ }^{1}$ Treatments were SAT $=$ saturated fatty acids (FA) from prilled, hydrogenated FA; INT = intermediate saturated FA as a mix of prilled, hydrogenated FA and calcium soaps of long-chain FA (LCFA); and UNS = partially unsaturated FA fed as Ca soaps of LCFA.

${ }^{2}$ Trt = Treatment effect; FS = effect of FA supplement; L = linear effect of substituting unsaturated FA for saturated FA; and $\mathrm{Q}$ = quadratic effect of substituting unsaturated FA for saturated FA.

${ }^{3} \mathrm{DE}=$ Digestible energy.
} 
Table 3. Effects of dietary fatty acid supplements on ruminal nutrient pool

\begin{tabular}{|c|c|c|c|c|c|c|c|c|c|}
\hline & \multicolumn{4}{|c|}{ Treatment LS means $^{1}$} & \multirow[b]{2}{*}{$\mathrm{SE}$} & \multicolumn{4}{|c|}{$P^{2}$} \\
\hline & Control & SAT & INT & UNS & & TRT & FS & $\mathrm{L}$ & Q \\
\hline Ruminal wet contents, $\mathrm{kg}$ & 86.6 & 85.7 & 80.7 & 74.4 & 3.7 & 0.04 & $<0.10$ & 0.02 & 0.87 \\
\hline Ruminal content volume, L & 101 & 97 & 93 & 89 & 4 & 0.06 & 0.04 & 0.05 & 0.94 \\
\hline Ruminal contents, \% DM & 16.9 & 17.1 & 17.4 & 16.9 & 0.4 & 0.72 & 0.62 & 0.73 & 0.35 \\
\hline \multicolumn{10}{|l|}{ Ruminal pool, kg } \\
\hline $\mathrm{DM}$ & 14.7 & 13.7 & 14.0 & 12.5 & 0.6 & 0.02 & 0.02 & 0.09 & 0.12 \\
\hline $\mathrm{OM}$ & 13.5 & 12.7 & 12.9 & 11.6 & 0.5 & 0.02 & 0.03 & 0.09 & 0.10 \\
\hline $\mathrm{NDF}$ & 7.9 & 7.5 & 7.4 & 6.5 & 0.3 & $<0.01$ & 0.02 & 0.01 & 0.16 \\
\hline
\end{tabular}

\footnotetext{
${ }^{1}$ Treatments were SAT = saturated fatty acids (FA) from prilled, hydrogenated FA; INT = intermediate saturated FA as a mix of prilled, hydrogenated FA and calcium soaps of long-chain FA (LCFA); and UNS = partially unsaturated FA fed as Ca soaps of LCFA.

${ }^{2}$ Trt = Treatment effect; FS = effect of FA supplement; $\mathrm{L}=$ linear effect of substituting unsaturated FA for saturated FA; and $\mathrm{Q}$ = quadratic effect of substituting unsaturated FA for saturated FA.
}

in the ruminant liver to generate a possible satiety signal (Allen, 2000). Decreasing intake would only decrease availability of propionate and protein needed for milk production. Partitioning of excess fuels to adipose tissue without a negative feedback on intake allows maintenance of protein and gluconeogenic nutrient intake. Cows in this experiment had relatively low BCS (mean $=1.9)$ and replenishment of body energy reserves may have created a demand that limited accumulation of circulating fuels. Interestingly, cows on the INT gained less BW than those on UNS while still decreasing rumen fill (Table 3; Harvatine and Allen, 2006a). Because it does not appear that gut distention affected feed intake for INT, if the BW gain was directed, INT would be expected to increase intake to meet the desired $\mathrm{BW}$ gain. We speculate that the extent to which milk fat depression results in decreased feed intake depends upon gluconeogenic nutrient absorption from the diet, gluconeogenic metabolite demand by tissues, and the extent to which glucose and preformed FA are spared by depressed milk fat synthesis. It is reasonable to speculate that UNS failed to regulate energy homeostasis because the positive energy balance is from an excess of specific fuels, and not from an excess of more hypophagic metabolites.

A companion paper reports no effect of treatment on intake of 8 noncannulated cows fed the same diet (Harvatine and Allen, 2006a); these cows had greater DIM (29 d) and body condition (>1 BCS heavier). Increasing unsaturated FS did not decrease milk fat yield in this group. Milk FA profile reported in a companion paper (Harvatine and Allen, 2006a) clearly show differences in ruminal biohydrogenation intermediates between the two groups. Differences in ruminal FA biohydrogenation may explain variation in intake response to dietary FA reported in the literature and between the two cow groups in this experiment.

\section{Ruminal Pools}

Addition of FS decreased wet weight and volume of rumen contents because of a linear decrease with increasing unsaturated FS (Table 3). Treatments did not affect rumen DM percentage but FS decreased pool size of DM, OM, and NDF; DM and OM pool sizes tended to decrease, and NDF pool size decreased with increasing unsaturated FS. Rumen pools decreased in proportion to intake resulting in no difference in rumen nutrient turnover of DM, OM, or NDF (Harvatine and Allen, 2006b). The observation that increasing unsaturated FA decreased DMI and rumen digesta OM pool without affecting turnover of $\mathrm{OM}$ provides strong evidence that the intake depression is not from a brake that slows passage leading to increased digesta pool size and distension in the reticulorumen. However, distension still may have affected intake if physiological response to FA saturation altered the response threshold for physical fill in the central satiety center.

\section{Feeding and Chewing Behavior}

Intake is determined by the number and size of meals consumed over a day. Treatment did not affect total time spent eating or the number of meals, but increasing unsaturated FS linearly decreased meal size by 0.22 $\mathrm{kg}(P<0.03$; Table 4$)$. There were no treatment effects detected for meal length, meal frequency or intermeal interval. Unsaturated FS linearly increased eating rate. Addition of FS and FS saturation had no effect on chewing time per meal, or per kilogram of DMI, NDF, or forage NDF (Table 5). Changes in meal size are normally attributed to satiety, whereas changes in meal frequency or intermeal interval are attributed to hunger. It appears that intake of unsaturated FS during a meal stimulated satiety resulting in decreased meal size that was not compensated for by increased meal 
Table 4. Effects of dietary fatty acid supplements on meal patterns and water consumption

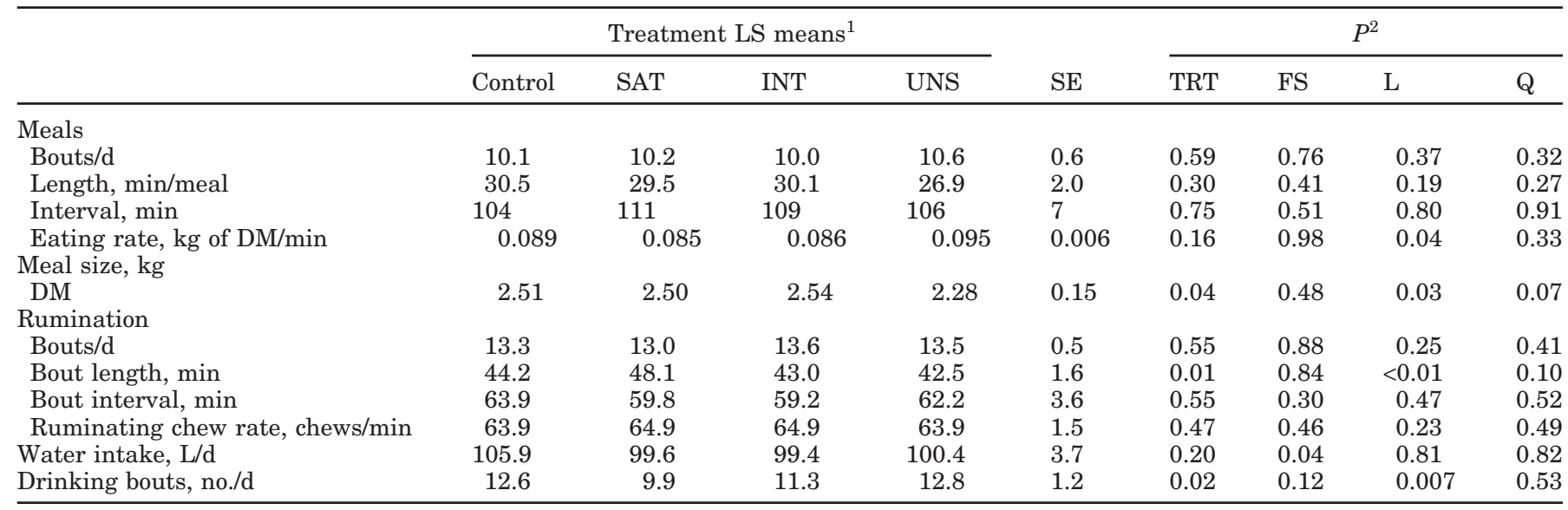

${ }^{1}$ Treatments were SAT $=$ saturated fatty acids (FA) from prilled, hydrogenated FA; INT = intermediate saturated FA as a mix of prilled, hydrogenated FA and calcium soaps of long-chain FA (LCFA); and UNS = partially unsaturated FA fed as Ca soaps of LCFA.

${ }^{2}$ Trt = Treatment effect; FS = effect of FA supplement; L = linear effect of substituting unsaturated FA for saturated FA; and Q = quadratic effect of substituting unsaturated FA for saturated FA.

number. The mechanism by which satiety is stimulated is not known but might involve gut peptide secretion (Choi and Palmquist, 1996; Litherland et al., 2005) or hepatic FA oxidation (Allen, 2000).

Saturated FS increased time spent ruminating compared with control and UNS. Saturated FS linearly increased time spent ruminating up to $56 \mathrm{~min}$ per d $(P$
$<0.01$ ). This increase in rumination time was because saturated FS linearly increased rumination bout length because there were no treatment effects on number of rumination bouts or interval between bouts. Saturated FS linearly increased rumination chewing time per bout, and quadratically affected rumination time per kilogram of DMI, NDF, and forage NDF. Allen (1997)

Table 5. Effects of dietary fatty acid supplements on chewing behavior

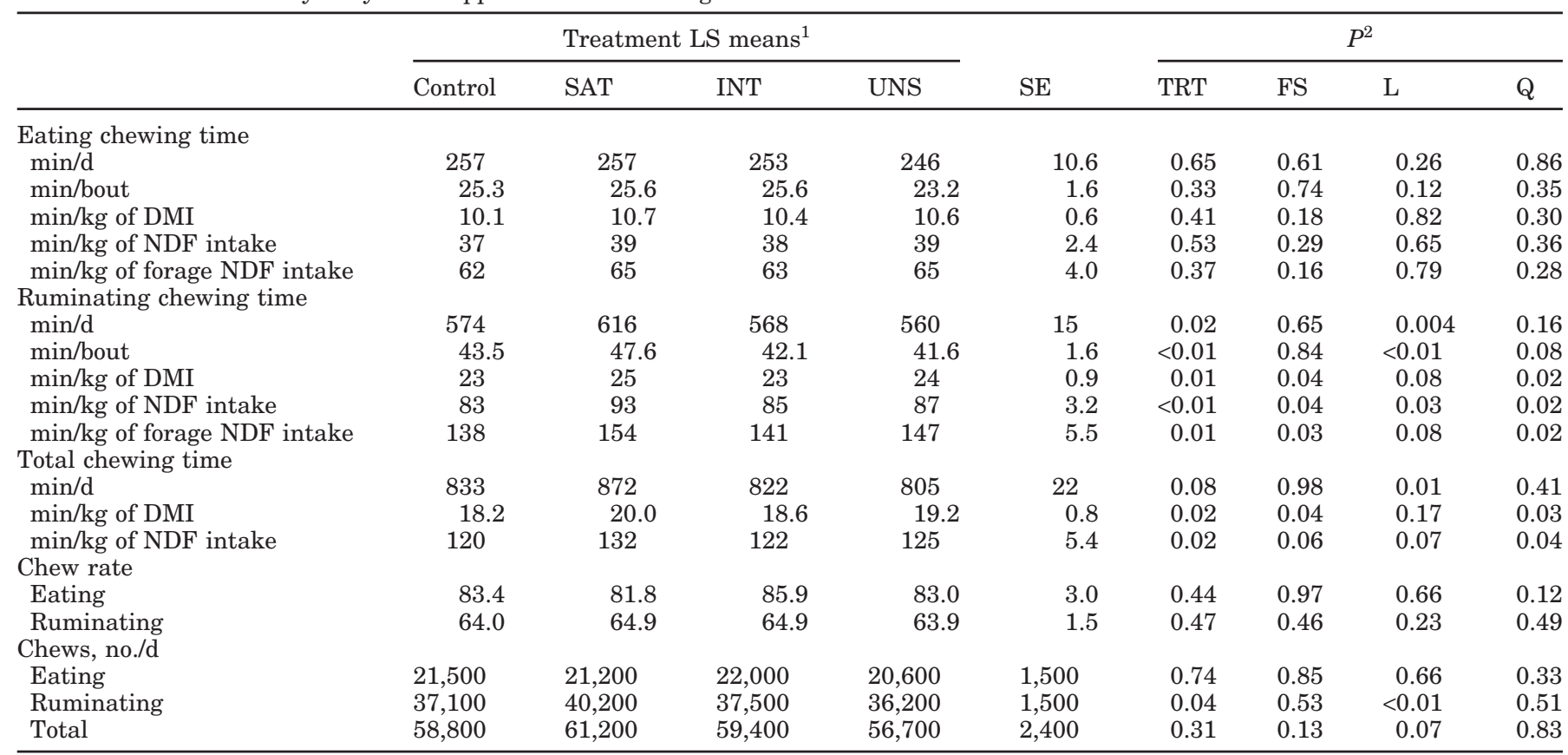

${ }^{1}$ Treatments were SAT = saturated fatty acids (FA) from prilled, hydrogenated FA; INT = intermediate saturated FA as a mix of prilled, hydrogenated FA and calcium soaps of long-chain FA (LCFA); and UNS = partially unsaturated FA fed as Ca soaps of LCFA.

${ }^{2} \mathrm{Trt}=$ Treatment effect; FS = effect of FA supplement; L = linear effect of substituting unsaturated FA for saturated FA; and Q = quadratic effect of substituting unsaturated FA for saturated FA. 
reported that total chewing time per day was not related to DMI across treatment means reported in the literature. In this experiment, the increased rumination for SAT was not because of increased DMI because rumination per kilogram of DM and fiber intake was quadratically affected by increasing saturated FS. Benson and Reynolds (2001) were unable to detect significant differences in rumination behavior with rapeseed infusion despite large decreases in time spent ruminating for some individual cows. We have previously observed that saturated FS increased time spent ruminating but did not change time spent eating compared with calcium salts of palm FA when observed by manual observation every 5 min (Harvatine and Allen, 2005). In the current experiment, the linear increase in rumination with increasing saturated FS appears to be because of increased duodenal flow of saturated FA because SAT increased rumination compared with control, whereas UNS was not different from control.

Total time spent chewing linearly increased with increasing saturated FS, but was not affected by FS. Similar to rumination, total time spent chewing per kilogram of DMI and NDF were quadratically affected by increasing saturated FS. There were no effects of treatment on rumination or chewing rate, showing that changes in chewing time relate directly to number of chews. Number of eating and ruminating chews per day followed similar patterns to the time spent in these activities. There was no treatment effect on total eating chews per day but increasing saturated FS linearly increased total rumination chews per day.

The changes in rumination behavior may be mediated through feed intake differences, associative effects on digestion, or stimulation of gut peptides. As previously mentioned, intake differences cannot explain the changes in chewing behavior because time spent ruminating per kilogram of NDF was affected by treatment. In addition, treatment diets differed in FA concentration, profile, and physical form but contained identical forage and concentrate components with the exception of substitution of rice hulls for FA. Diets were not expected to differ in effectiveness of stimulating rumination; chewing activity was related to forage NDF concentration but not total NDF concentration across treatment means reported in the literature (Allen, 1997), and forage NDF concentration was the same across treatments. It is unlikely that increased rumination for SAT was because of increased distention in the reticulorumen because digesta pool size and volume was numerically lower for SAT compared with control.

We have previously proposed that time spent ruminating may be related to reticular-rumen motility (Harvatine and Allen, 2005). Deswysen et al. (1987) reported a strong positive relationship between the number of rumen contractions and rumination time. We speculate that less rumination for the UNS compared with SAT is associated with reduced ruminal motility related to duodenal FA flow. Nicholson and Omer (1983) showed that intestinal infusion of unsaturated FA decreased rumen motility of sheep, and Grovum (1984) reported almost total cessation of rumen motility after $13 \mathrm{~h}$ of intragastric infusion of unsaturated fat compared with intravenous infusion. Unsaturated FA increased plasma concentrations of cholecystokinin (Choi and Palmquist, 1996) and glucagon-like-peptide-1 (Benson and Reynolds, 2001; Litherland et al., 2005), and direct intravenous infusions of cholecystokinin depressed reticular-rumen motility and intake in sheep (Grovum, 1981). These gut peptides are normally secreted in response to FA ingestion and affect gut motility (Reidelberger, 1994; Hellstrom and Naslund, 2001). Most experiments testing stimulation of gut peptide secretion used PUFA treatments and no fat controls. The effect of saturated FA on gut peptide secretion and gut motility is not understood and the mechanism for the increase in rumination time for SAT compared with control is unknown.

Addition of FS decreased water consumption presumably due to decreased OM digested in the rumen. Interestingly, increasing saturated FS linearly decreased the number of drinking bouts compared with control (9.9 and 12.6 bouts/d, respectively) but did not affect water intake. The interaction of FA type, rumination, and feeding behavior with drinking activity is not understood.

\section{Nutrient Selection}

Control treatment increased selection against NDF and total FA and for starch compared with FS (Table 6). The control diet contained lower total FA concentration and slightly higher NDF concentration because of the inclusion of rice hulls instead of FS. Selection against both NDF and FA for the control diet might be explained by selection against cottonseeds, which are a source of both components. Unsaturated FA linearly increased selection against gross energy and FA. This might be because of palatability differences in the fat sources, although it is not consistent with the linear increase in eating rate with increasing unsaturated FS. An alternative explanation is that selection against gross energy concentration was because of decreased energy requirements experienced during milk fat depression with increasing unsaturated FS. Differences in selection were very small but highly significant. Small differences may be expected because feeding to $15 \%$ orts limits the ability to select because of the amount of feed available, and a very large difference in composition of 
Table 6. Effects of dietary fatty acid supplments on nutrient selection

\begin{tabular}{|c|c|c|c|c|c|c|c|c|c|}
\hline \multirow{2}{*}{$\begin{array}{l}\text { Nutrient } \\
\text { selection }^{3}\end{array}$} & \multicolumn{4}{|c|}{ Treatment LS means $^{1}$} & \multirow[b]{2}{*}{$\mathrm{SE}$} & \multicolumn{4}{|c|}{$P^{2}$} \\
\hline & Control & SAT & INT & UNS & & TRT & FS & $\mathrm{L}$ & $\mathrm{Q}$ \\
\hline $\mathrm{NDF}$ & 95.6 & 98.8 & 99.3 & 99.2 & 1.4 & 0.08 & 0.01 & 0.80 & 0.81 \\
\hline Indigestible NDF & 99.2 & 100.9 & 101.2 & 99.0 & 1.5 & 0.37 & 0.37 & 0.23 & 0.34 \\
\hline Starch & 102.1 & 99.0 & 99.0 & 99.8 & 1.2 & 0.08 & 0.01 & 0.54 & 0.74 \\
\hline $\mathrm{CP}$ & 100.4 & 100.2 & 100.6 & 100.3 & 0.29 & 0.77 & 0.90 & 0.89 & 0.31 \\
\hline Gross energy & 99.6 & 99.9 & 99.8 & 99.6 & 0.08 & $<0.01$ & 0.12 & $<0.01$ & 0.33 \\
\hline Total fatty acids & 99.4 & 101.3 & 100.9 & 101.7 & 0.68 & 0.10 & 0.02 & 0.63 & 0.43 \\
\hline
\end{tabular}

${ }^{1}$ Treatments were SAT = saturated fatty acids (FA) from prilled, hydrogenated FA; INT = intermediate saturated FA as a mix of prilled, hydrogenated FA and calcium soaps of long-chain FA (LCFA); and UNS = partially unsaturated FA fed as Ca soaps of LCFA.

${ }^{2}$ Trt $=$ Treatment effect; FS = effect of FA supplement; $\mathrm{L}=$ linear effect of substituting unsaturated FA for saturated FA; and $\mathrm{Q}$ = quadratic effect of substituting unsaturated FA for saturated FA.

${ }^{3}$ Selection $=($ nutrient concentration consumed/nutrient concentration fed $) \times 100$.

orts is needed to change the composition of diet consumed. The biological significance of these differences in selection may be much larger in group-fed animals and animals with larger amounts of feed available for selection.

\section{Ruminal $\mathrm{pH}$}

Daily mean, minimum, and maximum $\mathrm{pH}$ were not changed by treatment, but $\mathrm{pH}$ range and variance were linearly increased by increasing saturated FS (Table 7). The range and variance in ruminal $\mathrm{pH}$ for UNS was not different from the control diet, but SAT increased $\mathrm{pH}$ range and variance. Increased $\mathrm{pH}$ range and variance with increasing saturated FS is not likely because of meal size as it did not differ between control and SAT. However, ruminal nutrient digestion and ruminal kinetics were modified by saturated FS (Harvatine and Allen, 2006b). Saturated FS decreased ruminal digestion of NDF through increased ruminal fractional passage rate and decreased ruminal fractional digestion rate of potentially digestible NDF. Increasing saturated FS only tended to decrease ruminal VFA concentration. Changes in ruminal $\mathrm{pH}$ range and variance may be due to differences in ruminal digestion with SAT.

\section{CONCLUSIONS}

Increasing dietary energy density with fat supplements may not increase digestible energy intake. Direct and indirect hypophagic effects of unsaturated FA are not separable because FA and fuel type modify shortand long-term physiology. The reduction in feed intake from unsaturated fat supplements is through decreased meal size without an increase in meal frequency. Addition of saturated fat increases rumination bout length and rumination time per day, possibly through modification of gut peptide secretion.

\section{ACKNOWLEDGMENTS}

We wish to acknowledge MS Specialty Nutrition (Dundee, IL) for partial financial support of this re-

Table 7. Effects of dietary fatty acid supplements on ruminal $\mathrm{pH}$

\begin{tabular}{|c|c|c|c|c|c|c|c|c|c|}
\hline & \multicolumn{4}{|c|}{ Treatment LS means ${ }^{1}$} & \multirow[b]{2}{*}{$\mathrm{SE}$} & \multicolumn{4}{|c|}{$P^{2}$} \\
\hline & Control & SAT & INT & UNS & & TRT & FS & $\mathrm{L}$ & $\mathrm{Q}$ \\
\hline Mean & 5.97 & 5.99 & 6.05 & 6.01 & 0.06 & 0.76 & 0.50 & 0.74 & 0.46 \\
\hline Minimum & 5.42 & 5.34 & 5.42 & 5.42 & 0.05 & 0.61 & 0.58 & 0.29 & 0.50 \\
\hline Maximum & 6.66 & 6.66 & 6.67 & 6.56 & 0.06 & 0.33 & 0.29 & 0.23 & 0.35 \\
\hline Range & 1.13 & 1.31 & 1.25 & 1.15 & 0.05 & 0.02 & 0.03 & $<0.01$ & 0.62 \\
\hline Variance & 0.11 & 0.14 & 0.13 & 0.1 & 0.01 & 0.01 & $<0.10$ & 0.005 & 0.46 \\
\hline Standard deviation & 0.32 & 0.37 & 0.35 & 0.31 & 0.02 & 0.01 & 0.08 & 0.005 & 0.50 \\
\hline Time $<6.0, \mathrm{~h}$ & 12.3 & 11.5 & 9.9 & 10.9 & 1.3 & 0.53 & 0.30 & 0.72 & 0.35 \\
\hline Area below $6.0, \mathrm{~h}$ & 497 & 470 & 376 & 380 & 73 & 0.51 & 0.30 & 0.38 & 0.56 \\
\hline
\end{tabular}

\footnotetext{
${ }^{1}$ Treatments were SAT $=$ saturated fatty acids (FA) from prilled, hydrogenated FA; INT = intermediate saturated FA as a mix of prilled, hydrogenated FA and calcium soaps of long-chain FA (LCFA); and UNS = partially unsaturated FA fed as Ca soaps of LCFA.

${ }^{2}$ Trt $=$ Treatment effect; FS = effect of FA supplement; L = linear effect of substituting unsaturated FA for saturated FA; and $\mathrm{Q}=$ quadratic effect of substituting unsaturated FA for saturated FA.
} 
search. We also thank N. K. Ames for performing duodenal and ruminal cannulations, and D. G. Main, R. A. Longuski, Y. Ying, M. Oba, C. S. Mooney, J. A. Voelker, C. C. Taylor, R. E. Kreft, and the staff of the Michigan State University Dairy Cattle Teaching and Research Center for their assistance in this experiment.

\section{REFERENCES}

Allen, M. S. 1997. Relationship between fermentation acid production in the rumen and the requirement for physically effective fiber. J. Dairy Sci. 80:1447-1462.

Allen, M. S. 2000. Effects of diet on short-term regulation of feed intake by lactating dairy cattle. J. Dairy Sci. 83:1598-1624.

Baumgard, L. H., E. Matitashvili, B. A. Corl, D. A. Dwyer, and D. E. Bauman. 2002. Trans-10, cis-12 conjugated linoleic acid decreases lipogenic rates and expression of genes involved in milk lipid synthesis in dairy cows. J. Dairy Sci. 85:2155-2163.

Benson, J. A., and C. K. Reynolds. 2001. Effects of abomasal infusion of long-chain fatty acids on splanchnic metabolism of pancreatic and gut hormones in lactating dairy cows. J. Dairy Sci. 84:1488-1500.

Bremmer, D. R., L. D. Ruppert, J. H. Clark, and J. K. Drackley. 1998. Effects of chain length and unsaturation of fatty acid mixtures infused into the abomasum of lactating dairy cows. J. Dairy Sci. 81:176-188.

Choi, B. R., and D. L. Palmquist. 1996. High fat diets increase plasma cholecystokinin and pancreatic polypeptide, and decrease plasma insulin and feed intake in lactating cows. J. Nutr. 126:2913-2919.

Christensen, R. A., J. K. Drackley, D. W. LaCount, and J. H. Clark. 1994. Infusion of four long-chain fatty acid mixtures into the abomasum of lactating dairy cows. J. Dairy Sci. 77:1052-1069.

Dado, R. G., and M. S. Allen. 1993. Continuous computer acquisition of feed and water intake, chewing, reticular motility, and ruminal pH of cattle. J. Dairy Sci. 76:1589-1600.

DeLuca, D. D., and T. C. Jenkins. 2000. Feeding oleamide to lactating Jersey cows. 2. Effects on nutrient digestibility, plasma fatty acids, and hormones. J. Dairy Sci. 83:569-576.

Deswysen, A. G., W. C. Ellis, and K. R. Pond. 1987. Interrelationships among voluntary intake, eating and ruminating behavior and ruminal motility of heifers fed corn silage. J. Anim. Sci. 64:835-841.

Drackley, J. K. 2000. Lipid Metabolism. Pages 97-119 in Farm animal metabolism and nutrition. J. P. F. D'Mello, ed. CABI Pub., Wallingford, UK.

Drackley, J. K., T. H. Klusmeyer, A. M. Trusk, and J. H. Clark. 1992. Infusion of long-chain fatty acids varying in saturation and chain length into the abomasum of lactating dairy cows. J. Dairy Sci. 75:1517-1526.

Grovum, W. L. 1981. Factors affecting the voluntary intake of food by sheep. 3 . The effect of intravenous infusions of gastrin, chole- cystokinin and secretin on motility of the reticulo-rumen and intake. Br. J. Nutr. 45:183-201.

Grovum, W. L. 1984. Control of digestion and metabolism in ruminants. Pages 18-40 in Proc. Sixth Int. Symp. Rumin. Physiol. L. P. Milligan, W. L. Grovum, and A. Dobson, ed. Prentice Hall, Englewood Cliffs, NJ.

Harvatine, K. J., and M. S. Allen. 2005. The effect of production level on feed intake, milk yield, and endocrine responses to two fatty acid supplements in lactating cows. J. Dairy Sci. 88:4018-4027.

Harvatine, K. J., and M. S. Allen. 2006a. Effects of fatty acid supplements on milk yield and energy balance of lactating dairy cows. J. Dairy Sci. 89:1081-1091.

Harvatine, K. J., and M. S. Allen. 2006b. Effects of fatty acid supplements on ruminal and total tract nutrient digestion in lactating dairy cows. J. Dairy Sci. 89:1092-1103.

Harvatine, K. J., and M. S. Allen. 2006c. Effect of fatty acid supplements on fractional rate of ruminal biohydrogenation in lactating dairy cows. J. Nutr. (accepted)

Hellstrom, P. M., and E. Naslund. 2001. Interactions between gastric emptying and satiety, with special reference to glucagon-like peptide-1. Physiol. Behav. 74:735-741.

Jenkins, T. C. 1998. Fatty acid composition of milk from Holstein cows fed oleamide or canola oil. J. Dairy Sci. 81:794-800.

Jenkins, T. C. 2000. Feeding oleamide to lactating Jersey cows 1. Effects on lactation performance and milk fatty acid composition. J. Dairy Sci. 83:332-337.

Litherland, N. B., S. Thire, A. D. Beaulieu, C. K. Reynolds, J. A. Benson, and J. K. Drackley. 2005. Dry matter intake is decreased more by abomasal infusion of unsaturated free fatty acids than by unsaturated triglycerides. J. Dairy Sci. 88:632-643.

Nicholson, T., and S. A. Omer. 1983. The inhibitory effect of intestinal infusions of unsaturated long-chain fatty acids on forestomach motility of sheep. Br. J. Nutr. 50:141-149.

Perfield, J. W., II, G. Bernal-Santos, T. R. Overton, and D. E. Bauman. 2002. Effects of dietary supplementation of rumen-protected conjugated linoleic acid in dairy cows during established lactation. J. Dairy Sci. 85:2609-2617.

Peterson, D. G., E. A. Matitashvili, and D. E. Bauman. 2003. Dietinduced milk fat depression in dairy cows results in increased trans-10, cis-12 CLA in milk fat and coordinated suppression of mRNA abundance for mammary enzymes involved in milk fat synthesis. J. Nutr. 133:3098-3102.

Reidelberger, R. D. 1994. Cholecystokinin and control of food intake. J. Nutr. 124(Suppl. 8):1327S-1333S.

SAS Institute. 2003. JMP. User's Guide: Statistical Discovery Software. Version 5 ed. SAS Inst., Inc., Cary, NC.

Shingfield, K. J., D. E. Beever, C. K. Reynolds, S. K. Gulati, D. J. Humphries, B. Lupoli, G. Hervas, and M. J. Griinari. 2004. Effect of rumen protected conjugated linoleic acid on energy metabolism of dairy cows during early to mid-lactation. J. Dairy Sci. 87(Suppl. 1):307. (Abstr.)

Wu, Z., O. A. Ohajuruka, and D. L. Palmquist. 1991. Ruminal synthesis, biohydrogenation, and digestibility of fatty acids by dairy cows. J. Dairy Sci. 74:3025-3034. 